\title{
E-learning's usability measurement toward students with myopia visual impairment
}

\author{
AG Pradnya Sidhawara ${ }^{1}$, Djoko Budiyanto Setyohadi ${ }^{1}$, Luciana Triani Dewi ${ }^{2}$, and Sri Kusrohmaniah ${ }^{3}$ \\ ${ }^{1}$ Department of Informatics Engineering, Faculty of Industrial Technology, Atma Jaya Yogyakarta University, Yogyakarta - \\ Indonesia \\ ${ }^{2}$ Department of Industrial Engineering, Faculty of Industrial Technology, Atma Jaya Yogyakarta University, Yogyakarta - \\ Indonesia \\ ${ }^{3}$ Department of Psychology, Faculty of Psychology, Gadjah Mada University, Yogyakarta - Indonesia
}

\begin{abstract}
Usability in e-learning is closely related to user interaction, so the e-learning interface needs to be taken into account. In e-learning, the user interface is an important factor of visual interaction between users and learning resources. Related to this, the user's vision aspect can affect the performance of elearning usage, especially usability problem, so the study about usability related to user's vision needs to be done. This study measuring the usability of e-learning using USE Questionnaire and supported by eyetracking technology. The results were compared between users with visual impairment and users with normal vision. The results obtained are, the usability variables have a correlation with each other. The four variables, which have a correlation to the variable tasks completion by the respondents (Task), are Ease of Learn, Ease of Use, Satisfaction, and Usefulness. This study shows that myopia visual impairment not causing difficulty in task completion. This is demonstrated in relatively similar user interactions, between normal-sighted users and abnormally-sighted users. The tendency to focus on web page elements per task for both groups of respondents are on elements such as announcement lists, course lists, navigation bars, drop-down menus, links and login text-boxes.
\end{abstract}

Keywords: usability; user interface; e-learning; eye tracker.

\section{Introduction}

According to ISO $9241-11$ of 1998 , usability is a measurement of the extent to which a particular consumer to achieve goals measured by efficiency, effectiveness, and satisfaction in context of use can use software. It also influenced by the interface display since the interface becomes an essential element of all web applications [1]. Nowadays many technology innovations depend on the user interface, where users facilitated to control and interact [2]. Usability reviewed through an evaluation called usability measurement.

Usability measurement might be supported by eye tracking. A person eyes' movement is assessed to know when an individual see at a specific time and the order of direction where their eyes move from one point to another [3]. Eye movements and reading patterns, also pupil diameter are indicators of thought processes and mental states that occur when visual information extraction [4]. Many published studies that focus on the usability of a website with the goal of web design optimization for potential user groups [5].

E-learning is technological innovation where teaching and learning activities use computer, memory, and computer network [6]. Web-based e-learning is one of the influential learning resources that education institutes use today. The interface of e-learning becomes aspect that needs attention as the interface is the interaction point between the user and the learning source [6]. The visualization, as a main of interface, will affect the user [7]. Through the interface, users can get information, especially learning materials, and furthermore the appropriate interface design will enhance the use of elearning.

Students with visual impairment having difficulties in obtaining information visually [8]. From the pre-survey that done at Atma Jaya Yogyakarta University, known about 126 of 227 respondents are students with visual impairment. The visual impairments that many students have in UAJY are nearsightedness or myopia and astigmatism. There are 89 students with nearsightedness, 9 students with astigmatism, and 28 students have both. This suggests that students with visual impairment of myopia and astigmatism become a significant group among students.

This research aims to suggest alternative ways of measuring the usability of a website interface e-learning and comparing the user's interaction on the website interface between users with visual impairments and normal vision with eye-tracking technology. Hopefully,

* Corresponding author: djokobdy@gmail.com 
improvement on e-learning would increase students' interest in digital learning and slowly convert paper-based learning in order to contribute development of lowcarbon society.

\section{Literature Review}

E-learning become great influence in learning activity nowadays. Provides great flexibilities on study method whether it's instructor-led or self-study courses. Learning process could happen anywhere and anytime using computer and internet technology, without reducing educators' role significantly [9]. For example, Moodle examined by previous exploratory study in aim to get an insight of Moodle's usability. Found that Moodle have high attractiveness and fulfill the satisfaction of its users. Nevertheless, more research needed to improve users' comfortability when interaction with interface of learning software happens [10].

Web interface design plays an important role in students' interactions. Its' appearance will affect how students access the content and interact with other users. Especially the properties of web page elements. Some issues identified with label, color, and font. Change of color combination and increase of font size needed to improve visibility of web page elements toward students [11]. Another improvement needed on combination of easy navigation element such as arrows and visualization of bullets or numbers [12].

Usability implementation not only limited on web platform. For example, usability theory based on ISO 9241-11 implemented for designing m-learning interface [13]. Emotional aspect influence analyzed for interface design that runs on a mobile platform. Then data collection questionnaire was analyzed using One-Way ANOVA method [7].

Next study found the usability of the portal website, analyze the concepts fit and web interface design from the usability for instructors and students, as well as conformity with ideal conditions. Tested criteria according to usability criteria of ISO standards including ease of use, ease of learn, steps of use, the time it takes for users, and consistency of website elements [5]. Interaction from the user's eyes with the interface of learning system needed to examined to see the users' behavior and interest also determine whether their attention remains centered on the learning system [3].

Research with aims to examine the relationship between learning support technology and experience in online learning by students with visual impairments was held. Researchers adopt a user-centered cognitive approach. It used to understand students' thinking processes when experiencing learning difficulties, also represent problems from the students' needs and abilities in online interaction [14].

Other researcher also aims to find out the usability of a university web site and identifying problems encountered for students who have visual impairment.
The usability criteria tested include ease of use, ease of use regarding usage steps, user time, and consistency of web site elements. Utilization and user satisfaction of the website obtained by questionnaire and interview [8]. A case study on the implementation of guidelines for web pages that have full accessibility for users with visual impairments also been held [15].

Research by the author used quasi-experiment method with an eye-tracker tool and usability measurement questionnaire. Usability criteria which being tested adopt criteria that were used in USE Questionnaire (Usability, Satisfaction, Easy of Use) which are Usefulness, Ease of Use, Easy of Learn, and Satisfaction.

\section{Methodology}

Sampling method used is Purposive Sampling. This method aims to capture significant variations of groups with specific characteristics. Samples used in this study are group of students with visual impairment consist 30 people and a group of students with a normal vision consists of 30 people from Atma Jaya Yogyakarta University students of Faculty of Industrial Technology and Faculty of Economics, in consideration of highly frequent usage of the website e-learning. The number of 30 respondents per group to meet the minimum rules of T-Student table statistics also aim for optimal heatmap visualization result from the eye-tracking data processing [16]. Students who are willing to be respondents provided with informed consent and personal data sheets.

Here are the steps and procedures of data collection of respondents:

1. Experimenter explains to the respondent a description of the research activities, give instructions on the task, and ask for written consent from the respondent to undergo the experiment.

2. Respondent entered the room for experiments and calibrated the eye tracker tool to the respondent's eyes.

3. Respondent perform tasks without the help of an experimenter. Tasks performed as many as five tasks that are a form of adaptation of tasks from previous study [8]. Tasks include content search, accessibility or navigation, and file retrieval.

4. Respondent completed the test followed by filling the questionnaire.

Questionnaires data obtained were 53 respondents consisting of 39 students of Industrial Technology Faculty and 14 Economics Faculty. There are 38 male students and 15 female students and for the duration of internet use in doing the coursework as well as the frequency of use of the website e-learning respondents 
vary. For duration of the use of the internet in doing most college tasks are limited to 1-3 hours and the use of the website e-learning in a week as much as 4-6 times.

\section{Results and Discussion}

Descriptive statistical analysis used for the results of questionnaire processing. The independent variables of this research are user demography such as Faculty, Gender, Duration of internet usage for assignment, the Frequency of e-learning usage, and Vision condition. The dependent variable is the duration of the work on the assignment, and the results of a questionnaire that contains Ease of Learn, Ease of Use, Satisfaction, Usefulness, and Task.

Validity and reliability test done to determine the items of the questionnaire that processed in the form of variables to be tested. Questions of the original inquiry amounted to 32 with the amount of incoming data amounted to 53 data. Validity test using comparison with table $\mathrm{R}$ for Degree of Freedom $=51$ has value $\mathrm{R}=$ 0.2706 .

There are some items, which have R-value less than the values in R table, they are TASK1, TASK3, TASK6, TASK7 items. These items eliminated from the item in case of forming the variables to be tested. Cronbach's alpha shows the value of each item questionnaire more than 0.7 , so the questionnaire has good reliability.

Outlier test done by changing the data value into Zscore and determining the outlier threshold value. The outlier threshold value used is 1.96. There are six respondents classified as extreme and outlier data; they are respondents with number $6,10,13,31,41,46$. The data numbers $6,10,13$ is an outlier and number 31 is the extreme data in Usefulness variable. In Satisfaction variable, data number 46 becomes outlier with Z-score 2.90. Data number 41 becomes data outlier on Task variable with Z-score value -3.14. No outlier data on Ease of Learn and Ease of Use.

The normality of data distribution tested using the Shapiro-Wilk method and obtained the result that four of the five variables tested have abnormal data distribution. The variable that shows the value of SIG less than 0.05 is Ease of use variable, Ease of learning, Satisfaction, and Task. Usefulness variables have a relatively normal data distribution with the number of the significance of 0.2 . Seeing the tendency of distributed data is not normal then used non-parametric analysis tool because it does not require the normal distribution of data.

The Kruskal-Wallis test used to check if there any significant difference between demographic variables in test variables. The results of Faculty demographic tests on Ease of Learn, Ease of Use, and Usefulness variables show a value of more than 0.05 which means that faculty differences do not affect the three of five variables tested. For Satisfaction and Task, variables show the existence of Faculty demography influence with the number of significance value of 0.034 for Satisfaction variable and 0.042 for Task variable.

For demographic variables Gender, Internet Usage, Use of E-learning, and Vision Conditions, test results for all demographics show values that are more than specified alpha values. No significant difference was found on the variable ease of learn, ease of use, usefulness, user satisfaction, and performing tasks.

Table 1. Kruskal Wallis Test for Faculty Demography

\begin{tabular}{|l|l|r|l|r|r|}
\hline & $\begin{array}{l}\text { USEFUL } \\
\text { NESS }\end{array}$ & $\begin{array}{l}\text { EASEOF } \\
\text { USE }\end{array}$ & $\begin{array}{l}\text { EASE } \\
\text { OFLEARN }\end{array}$ & $\begin{array}{l}\text { SATISF } \\
\text { ACTIO } \\
\text { N }\end{array}$ & TASK \\
\hline $\begin{array}{l}\text { Chi- } \\
\text { Square }\end{array}$ & .469 & .720 & .033 & 4,513 & 4.121 \\
\hline df & 1 & 1 & 1 & 1 & 1 \\
\hline $\begin{array}{l}\text { Asympt } \\
\text { otic Sig. }\end{array}$ & .493 & .396 & .856 & .034 & .042 \\
\hline
\end{tabular}

Statistically, Kruskal Wallis results show that different vision conditions don't have significant implications for the work performed by the respondents represented by the Task variable. The result of eye tracker data processing in the form of heatmap also shows the same thing, shown in the collection of focus coordinate points. There are no differences in interface elements that are focused in the stages of task completion.

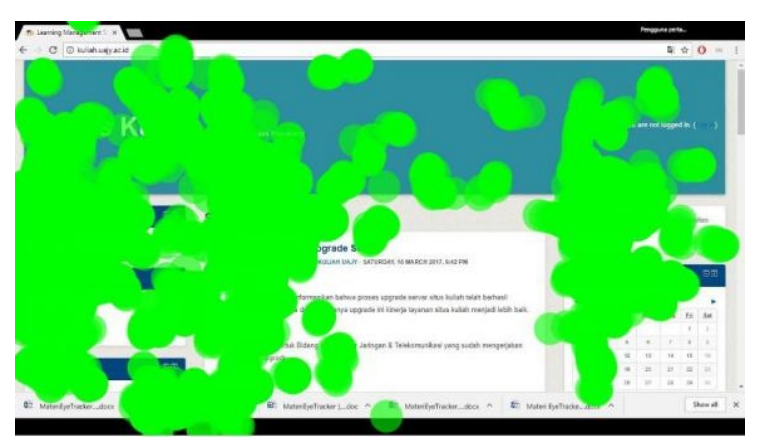

Fig. 1. Heatmap for Task 1 of respondents with normal vision.

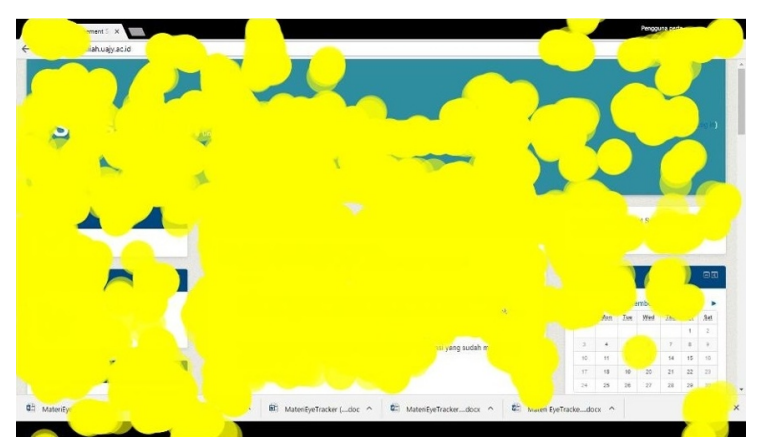

Fig. 2. Heatmap for Task 1 of respondents with visual impairment myopia. 


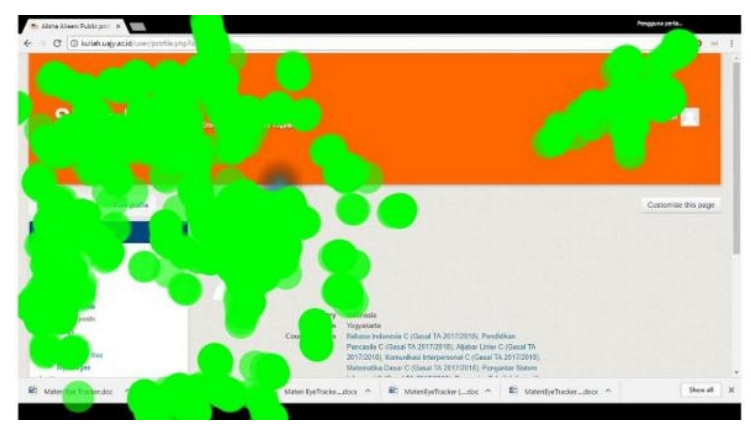

Fig. 3. Heatmap for Task 3 of respondents with normal vision.

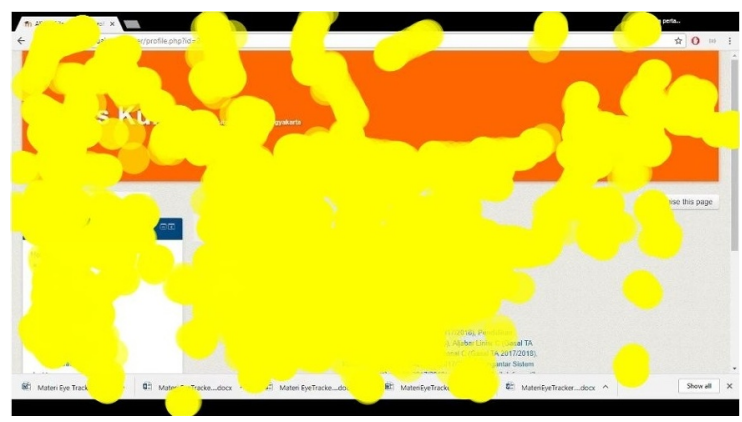

Fig. 4. Heatmap for Task 3 of respondents with visual impairment myopia.

The video recording of respondents' behaviour shows the habit of the respondents in using the website e-learning is more influential in the steps of task completion. For example, usage of navigation bar for searching of specific announcement in Task 1, which actually searchable in the middle of page. Highlighted web page element which contain selection items might become important anchor point for both group of respondents. This kind representation could influence the ability of user in read and remember page content, which affect users' preference for using the system [17]. Also in a previous study, visual attention of the user shifted from content to selection items with fixed position and hierarchical structure [18]. Users' visual attention tendency is focused on upper left part of the page. Upper-left part of webpage is more attractive, where navigation bar is placed [19].

In completion of Task 3 proven that some respondents still took a step in using dropdown menu on right side to access their profile web page instead using navigation bar. Although both elements contain selection items, some of respondents' habit in using drop-down could affects more and drop-down menu on the right column have iconic representations by using profile name and photo which might attract user's attention [20]

Spearman's correlation coefficients for variables Usefulness of the four other variables are of high value, and significance number is worth less than 0.05. Against Ease of Use variable, the number of significance 0.000 , also towards Satisfaction variable have the same value. Usefulness variable toward Ease of Learn variable significantly in value 0.004. Ease of Use and Ease of Learn variable also has a high correlation value toward the users' Satisfaction.
Significance number of the four variables of usability toward Task variable indicates values below the alpha $=0.05$ and most significant is the variable Ease of Use with the numerical value of the significance of 0.000 , followed by Ease of Learn with significant value 0.002, users' Satisfaction with value 0.011 , and Usefulness variable with value of 0.029 . This shows that the tested usability variable correlates with the task work done by the respondent.

Table 2. Spearman's Correlation of Usefulness, Ease of Use, Ease of Learn, Satisfaction, and Task variables

\begin{tabular}{|c|c|c|c|c|c|c|}
\hline & & $\begin{array}{l}\text { USEFU } \\
\text { LNESS }\end{array}$ & $\begin{array}{l}\text { EASE } \\
\text { OF } \\
\text { USE }\end{array}$ & $\begin{array}{l}\text { EASE } \\
\text { OF } \\
\text { LEARN }\end{array}$ & $\begin{array}{l}\text { SATIS } \\
\text { FACT } \\
\text { ION }\end{array}$ & TASK \\
\hline \multirow{3}{*}{$\begin{array}{l}\text { USEFUL } \\
\text { NESS }\end{array}$} & $\begin{array}{l}\text { Coeff. } \\
\text { Correlation }\end{array}$ & 1,000 & $.554 \cdots$ & .408 & .507 & $.320^{\circ}$ \\
\hline & $\begin{array}{l}\text { Significance } \\
\text { (2-tailed) }\end{array}$ & $\cdot$ & .000 & .004 & .000 & .029 \\
\hline & $\mathbf{N}$ & 47 & 47 & 47 & 47 & 47 \\
\hline \multirow{3}{*}{$\begin{array}{l}\text { EASE OF } \\
\text { USE }\end{array}$} & $\begin{array}{l}\text { Coeff. } \\
\text { Correlation }\end{array}$ & .554 & 1,000 & $.822 \cdots$ & $.576 "$ & $.568 \cdots$ \\
\hline & $\begin{array}{l}\text { Significance } \\
\text { (2-tailed) }\end{array}$ & .000 & . & .000 & .000 & .000 \\
\hline & $\mathbf{N}$ & 47 & 47 & 47 & 47 & 47 \\
\hline \multirow{3}{*}{$\begin{array}{l}\text { EASE OF } \\
\text { LEARN }\end{array}$} & $\begin{array}{l}\text { Coeff. } \\
\text { Correlation }\end{array}$ & .408 & $.822 *$ & 1,000 & $.498 *$ & .433 \\
\hline & $\begin{array}{l}\text { Significance } \\
\text { (2-tailed) }\end{array}$ & .004 & .000 & . & .000 & .002 \\
\hline & $\mathbf{N}$ & 47 & 47 & 47 & 47 & 47 \\
\hline \multirow{3}{*}{$\begin{array}{l}\text { SATISFA } \\
\text { CTION }\end{array}$} & $\begin{array}{l}\text { Coeff. } \\
\text { Correlation }\end{array}$ & .507 & $.576 "$ & .498 & 1,000 & .368 • \\
\hline & $\begin{array}{l}\text { Significance } \\
\text { (2-tailed) }\end{array}$ & .000 & .000 & .000 & . & .011 \\
\hline & $\mathbf{N}$ & 47 & 47 & 47 & 47 & 47 \\
\hline \multirow{3}{*}{ TASK } & $\begin{array}{l}\text { Coeff. } \\
\text { Correlation }\end{array}$ & $.320^{\circ}$ & .568 " & .433 & .368 & 1,000 \\
\hline & $\begin{array}{l}\text { Significance } \\
\text { (2-tailed) }\end{array}$ & .029 & .000 & .002 & .011 & \\
\hline & $\mathbf{N}$ & 47 & 47 & 47 & 47 & 47 \\
\hline
\end{tabular}

Prior research suggests that Ease of Use, which consists of Ease of Learn and Ease of Use, towards Usefulness has a relationship and affects one another. If there is an increase in the Ease of Use rating, then the rating of Usefulness improve and vice versa [21]. These three dimensions are considered to be most useful for measuring the usability of an interface. Spearman's correlation test results support Arnold Lund's suggestion, with the number of significance between Usefulness variables, Ease of Learn, Ease of Use, and Satisfaction shows four variables have a strong correlation with each other. 


\section{Conclusion}

The four variables have a correlation to the variable task completion by the respondent (Task). Ease of Use with the value of significance worth 0.000 , then followed by Ease of Learn variables with the value of 0.002 , Satisfaction with the value 0.011, and Usefulness variable with a value of 0.029 .

Interaction of respondents with normal eyesight and respondents with visual impairment toward the user interface of the website e-learning didn't encounter significant differences. The tendency of focus on web page elements per task for both groups of respondents is relatively the same. Visual impairment myopia and astigmatism do not cause difficulties with the task.

Suggestions for the further research are respondents quantity should be added for avoiding abnormal distribution of statistical data, eye-tracking data processing for heatmap could be more precise by separate color level which represent fixation duration of respondents' focus area.

Optimization for e-learning on navigation bar and dropdown menu usage for accessing links for Site News, My Course, My Profile. Both navigation elements shown to be frequently used in respondents' behavior.

\section{Acknowledgement}

This research has been supported by Data Engineering and Information System Research Group and Industrial Technology Faculty of Atma Jaya Yogyakarta University.

\section{References}

1. M. N. Islam \& H. Bouwman, An assessment of a semiotic framework for evaluating user-intuitive Web interface signs. Universal Access in the Information Society, p. 563- 582 (2015)

2. V. Cho, T. E. Cheng, \& W. J. Lai, The role of perceived user-interface design in continued usage intention of self-paced e-learning tools (2009)

3. R. Sungkur, M. Antoaroo, \& A. Beeharry, Eye Tracking System for Enhanced Learning Experiences, (2015)

4. R. Keith, Eye movements in reading and information processing: 20 years of research, (1998)

5. C. K. Prantner, The evaluation of the results of an eye tracking based usability tests of the so-called Instructor's Portal, (2015)

6. B. Faghih, D. M. R. Azadehfar, \& P. S. D. Katebi, User Interface Design for E-Learning Software, The International Journal of Soft Computing and Software Engineering [JSCSE], Vol. 3, No. 3, (2013)

7. D.B. Setyohadi, S. Kusrohmaniah,E. Christian, L.T. Dewi, \& B.P. Sukci, M-Learning Interface Design Based on Emotional Aspect Analysis, International
Conference on Intelligent Human Computer Interaction (pp. 276-287), (2016)

8. N. Menzi-Cetin, E. Alemdag, H.Tuzun \& M. Yildiz, Evaluation of a university website's usability for visually impaired, (2015)

9. J. E. Luaran, N. N. Samsuri, F. A. Nadzri, K. B. Mohamad Rom, A Study on The Student's Perspecitve on The Effectiveness of E-learning, Procedia - Social and Behavioral Sciences 123, 139-144, (2014)

10. A. Daneshmandnia, A Usability Study of Moodle, Proceedings of the Spring 2013 Mid-Atlantic Section Conference of the Ameircan Society of Engineering Education, (2013)

11. P. Ramakrisnan, A. Jaafar, F.H.A. Razak, D.A. Ramba, Evaluation of User Interface Design for Learning Management System: Investigating Student's Eye Tracking Pattern and Experiences, The $3^{\text {rd }}$ International Conference on $e$ Learning,(2012)

12. M. Radecky, P. Smutny, Evaluatiing User Reaction to User Interface Element Using Eye Tracking Technology, $15^{\text {th }}$ International Carpathian Control Conference (ICCC),(2014)

13. E. Zakharia, D.B. Setyohadi, Y.S. Purnomo, Perancangan Antarmuka Online Course Pada Perangkat Mobile Menggunakan Teori Usability, INFORMATIKA Vol. 12 No.1, (2016)

14. K. Kharade, H. Peese, Learning by E-learning for Visually Impaired Students: opportunities or again marginalization, (2012)

15. A.M. Michalska, C X. You, A. M. Nicolini, V. J. Ippolito \& W. Fink, Accessible Web Page Design for the Visually Impaired: A Case Study, International Journal of Human-Computer Interaction, 30:12, 995-1002, (2014)

16. K. Pernice, J. Nielsen, How to Conduct Eyetracking Studies, (2009)

17. H. Al-Samarraie, H. Selim, T. Teo, F. Zaqout, Isolation and Distintiveness in The Design of Elearning Systems Influence User Preferences, Interactive Learning Environments,(2016)

18. G. Rakoczi, Cast Your Eyes on Moodle: An Eye Tracking Study Investigating Learning with Moodle, Moodle.si $20104^{\text {th }}$ International Conference Proceedings, (2010)

19. H. Li, D. Che, X. Yuan, Y. Li, Research on Book Shopping Website Interface Based on The Eye Tracker, International Journal of Information Technology and Management, (2018)

20. G. Rakoczi, Analysis of Eye Movements in The Context of E-learning: Reccomendations for Eyeefficient User Interfaces, Dissertation, (2014)

21. A. Lund, Measuring usability with the USE questionnaire, ResearchGate, (2001) 